DOI: 10.12731/2070-7568-2020-4-347-369

УДК 338.27

\title{
ОРГАНИЗАЦИОННОЕ РАЗВИТИЕ УНИВЕРСИТЕТОВ В СТРАТЕГИЧЕСКОМ КОНТЕКСТЕ: ПРОБЛЕМЫ И ПЕРСПЕКТИВЫ ПРОЕКТА «5-100»
}

Мадьяров $A . A$.

В статье рассматриваются особенности организационного развития российских университетов в контексте реализации проекта «5-100» по повышению их международной конкурентоспособности.

Целью работы является формирование внутриорганизачионных механизмов организационного развития российских университетов посредством систематизации нормативной базы и подведения итогов по проекту «5-100». При этом использовались следующие основные методы исследования: анализ информации из открытых источников и включенное наблюдение 1 . В ходе подготовки статьи изучены нормативные документы и теоретические концепции, а также результаты исследований особенностей развития вузов, выявлены типичные черты российских университетов. На основе установленных характерных особенностей и проблем вузов РФ сформулированы рекомендации по обеспечению дальнейтего развития университетов в условиях инновачионной экономики.

Взаключении указывается на необходимость пересмотра существующих механизмов ичелеполагания и вовлечения ключевых заинтересованных сторон в стратегический прочуесс, формирования мотивирующей среды вуза, имплантации принципов организационной демократии при одновременном отказе от бюрократических иенностей.

Ключевые слова: организационное развитие; стратегический контекст; организационные патологии; стратегический прочесс; иерархия способностей; заинтересованные стороны; целеполагание.

\footnotetext{
${ }^{1}$ Включенное наблюдение - метод исследования, предусматривающий активное участие исследователя в деятельности организации и наблюдение за происходящими событиями изнутри.
} 


\section{ORGANIZATIONAL DEVELOPMENT OF UNIVERSITIES IN STRATEGICAL CONTEXT: PROBLEMS AND PERSPECTIVES OF PROJECT «5-100»}

\section{Madyarov A.A.}

The article examines the features of the organizational development of Russian universities in the context of the implementation of the «5-100» project to increase their international competitiveness.

The aim of the work is to form internal organizational mechanisms for the organizational development of Russian universities by systematizing the regulatory framework and analyzing the results of the «5-100» project. The following basic research methods were used: analysis of information from open sources and participant/included observation. During the preparation of the article, regulatory documents and theoretical concepts were studied, as well as the results of studies of the peculiarities of the development of universities, typical features of Russian universities were identified. Based on the identified characteristics and problems of Russian universities, recommendations have been formulated to ensure the further development of universities in an innovative economy.

In the conclusion, the need to revise the existing mechanisms of goal setting and involvement of key stakeholders into the strategic process, the formation of a motivating environment of universities, the implantation of the principles of organizational democracy, with the simultaneous rejection of bureaucratic values.

Keywords: organizational development; strategical context; organizational pathologies; strategic process; hierarchy of abilities; stakeholders; goal setting.

\section{Введение}

Современный университет, как участник социально-экономических отношений, является центром интеграции усилий различных заинтересованных сторон. В новом стратегическом контексте инновационной экономики трансформируется среда функционирова- 
ния организаций, выдвигая новые требования к постановке целей, методам и инструментам управления.

\section{Обзор литературы по теме исследования}

Начиная с 2012 года «в целях дальнейшего совершенствования государственной политики в области образования и науки и подготовки квалифицированных специалистов с учетом требований инновационной экономики» реализуется поставленная задача по «вхождению к 2020 году ... российских университетов в первую сотню ведущих мировых университетов согласно мировому рейтингу университетов» [1]. В октябре 2012 года указ №599 конкретизировали: появился «план мероприятий по развитию ведущих университетов, предусматривающих повышение их конкурентоспособности среди ведущих мировых научно-образовательных центров». Согласно распоряжению правительства РФ № 2006-р от 29.10.2012 (редакция от 12 мар 2016) вузамучастникам предписывалось следующее (систематизируем и расшифруем мероприятия) [6]:

1) в отношении организационно-нормативного обеспечения стратегического менеджмента вуза: разработка дорожных карт повышения международной конкурентоспособности (созданный «Совет по повышению конкурентоспособности ведущих университетов РФ» получил право вносить свои рекомендации по предоставлению господдержки, рассматривая требования к отбору вузов и программы повышения конкурентоспособности университетов России [5]),

2) в отношении развития кадрового потенциала: разработка мер по формированию кадрового резерва руководящего состава и по совершенствованию механизмов привлечения - закреплению молодых научно-педагогических кадров (в соответствии с методическими рекомендациями по подготовке отчетов вузов [4], «молодые кадры»-это лица в возрасте до 30-40 лет в зависимости от наличия ученой степени и гражданства), а также по обеспечению международной и внутрироссийской академической мобильности научно-педагогических работников,

3) в отношении образовательной деятельности: разработка новых образовательных программ в партнерстве с ведущими университе- 
тами и научными организациями, мер по привлечению студентов из ведущих зарубежных университетов, «проявивших творческие способности и интерес к научной (научно-исследовательской) деятельности» [4],

4) в отношении научно-исследовательской деятельности: постоянная актуализация перечня научно-исследовательских работ с учетом международных направлений исследований, реализация научно-исследовательских и опытно-конструкторских проектов с привлечением к руководству ведущих зарубежных и российских ученых, а также перспективных научных организаций и высокотехнологичных компаний, меняя (при необходимости) организационную структуру управления вуза.

Университеты-участники должны были обеспечивать предоставление подписанных ректорами отчетов об этапах реализации дорожных карт. В соответствии с перечнем требований [7] отчет по реализации плана мероприятий должен был содержать информацию (систематизируем перечень):

1) по результативности системы стратегического управления: о ходе реализации стратегических инициатив, достижении поставленных целей и задач (включая информацию о позиции вуза в международных общих - институциональных и предметных рейтингах); о предлагаемых вузом лучших практиках к тиражированию в системе высшего образования РФ; о проблемах реализации плана мероприятий; о доле доходов из внебюджетных источников в структуре доходов вуза, о целевом использовании средств субсидий; о совершенствовании системы управления вузом,

2) по образовательной деятельности: об удельном весе численности иностранных студентов в общей численности студентов; о партнерстве с ведущими зарубежными и российскими университетами, научными организациями, ассоциациями (в части разработки новых образовательных программ, привлечения иностранных студентов),

3) по научно-исследовательской деятельности: о количестве статей и цитирований в научных журналах, индексируемых в Web of Science и Scopus [2]; о разработке и реализации мер по продвиже- 
нию реферируемых научных журналов вузов - участников программы «5-100»,

4) по кадровой политике: об удельном весе численности иностранных научно-педагогических работников (далее - НПР) в общей численности НПР; о формировании эффективного механизма привлечения и закрепления молодых научно-педагогических кадров, как имеющих успешный опыт работы, так и студентов, аспирантов и стажеров; о формировании кадрового резерва руководящего состава вуза; о международной и внутрироссийской академической мобильности НПР.

Систематизируем базовые теоретические концепции исследования, раскрыв, в первую очередь, термин «организационное развитие» (далее - ОР):

1) ведущие профессора МГУ им. М.В. Ломоносова» В.И. Добреньков и А.И. Кравченко в своем 15-томном труде определяют процесс ОР, как осуществление «целенаправленных изменений и совершенствования эффективности организации за счет развития системы и методов управления»; при этом эффективность, по их мнению, повышается за счет вовлечения работников «в честное и открытое обсуждение возникающих проблем» [12, с. 382],

2) В.В. Щербина и Е.П. Попова, авторы монографии «Организационное развитие» приходят к выводу, что «под ОР понимается определенный тип направленных организационных изменений, логика и механизм протекания которых трактуются по-разному и часто достаточно экзотично» [28, с. 11],

3) Венделл Френч и Сесил Белл понимают под ОР решение проблем, выявленных в ходе организационной диагностики [32, с. 64-65],

4) те же исследователи из университетов США указывают, что OP стимулирует совершенствование организации на институциональном и индивидуальном уровнях, обеспечивая достижение кратко- и долгосрочных целей [33, с. 3],

5) профессор А.И. Пригожин классифицировал организационные патологии, определив их как препятствия для достижения поставленных целей [19] в процессе ОР, которые можно рассматривать в 
качестве симптомов, источников организационных проблем, причин ресурсных разрывов ${ }^{1}$,

6) международная консалтинговая компания Ваin ежегодно публикует рейтинг лучших инструментов менеджмента ${ }^{2}$ или ОР, востребованных на глобальном уровне [30],

7) некоторые авторы рассматривают ОР как процесс балансировки интересов разных стейкхолдеров ${ }^{3}$. Достижение стратегических целей, по их мнению, возможно только при условии органичного удовлетворения требований и ожиданий всех ключевых заинтересованных сторон.

Продолжая анализировать базовые теоретические концепции исследования, выделим подходы к определению субъектности и приоритетов развития.

Во-первых, матрица власти заинтересованных сторон Уинстанли $[24$, c. 46$]$ наряду со значимостью («кто или что реально имеет значение» в разработке стратегии) и учетом набора факторов (способность влиять на решения, легитимность требований, безотлагательность удовлетворения организацией требований) участниками процесса целеполагания по Аглу [24, с. 47] демонстрирует субъект-объектные взаимоотношения в ходе определения стратегических целей и приоритетных направлений, механизмов стратегического развития.

Во-вторых, по мнению известного российского специалиста в области управленческого консалтинга профессора А.И. Пригожина эффективность стратегического менеджмента напрямую зависит от происхождения целевых установок. Наиболее перспективной в этом смысле, по его мнению, является «ценностное целеполагание» [21, с. 103-104]. В отличии от заданного извне (пассивного) или конкурентного, когда акценты нередко смещаются в борьбе интересов (игнорируются факторы, оказывающие решающее влияние на выбор объектов для сравнения), происхождение целей по ценностям

${ }^{1}$ Ресурсные разрывы - недостаток или нехватка ресурсов и способностей организации, необходимых для ответа на внешние вызовы стратегического контекста.

${ }^{2}$ Инструменты менеджмента или management tools можно рассматривать как своего рода лекарства («интервенции» [32]) от внутриорганизационных заболеваний.

${ }^{3}$ Стейкхолдеры - заинтересованные стороны. 
может лучше всего способствовать повышению эффективности стратегического управления.

В-третьих, М. Портер в книге «Конкуренция» высказался о расстановке приоритетов развития в пользу повышения внутренних возможностей: деятельность за границей должна быть выборочной и дополняющей, направленной лишь на то, чтобы максимизировать конкурентные преимущества [18, с. 253].

\section{Постановка проблемы исследования}

Государство продолжает реформирование системы высшего образования, стимулируя дифференциацию вузов РФ по качеству образования [26]:

1) появилась группа элитарных вузов, с которыми связывалось решение задач по включению в международные рейтинги (проект «5-100»); в условиях ускоряющихся изменений актуальна подготовка «высококвалифицированных кадров широкого профиля для творческой деятельности»; элитарность - заданная извне «идеологема, не отражающая организационную природу вуза»; перспективность вуза связана, скорее, с развитием его динамических способностей и поэтому паттерн инновационного университета, находящегося в состоянии постоянных изменений, является более перспективной моделью развития вуза в новой экономике знаний, чем какие-либо внешние стимулы государства,

2) идея объединения науки и образования посредством включения всех преподавателей и студентов вуза во внутриорганизационные процессы оказывается практически нереализуемой в рамках бюрократических структур университетов: возникает противоречие между образовательными (рутинными) и исследовательскими (не рутинными) практиками: модель «профессиональной бюрократии» ориентирована на выполнение персоналом профессиональных норм, заданных внешними надзорными органами, которые контролируют соблюдение вузами образовательных стандартов, но это не гарантирует востребованности выпускников вузов на российском и международном рынках труда. 
По итогам 2020 г. не все поставленные цели проекта «5-100» были достигнуты. Некоторым экспертам удалось спрогнозировать это еще в 2018 г. [23, с. 236]: «правительство РФ не сможет обеспечить вхождение к 2020 г. пяти российских университетов в первую сотню ведущих мировых университетов согласно авторитетным мировым рейтингам».

Демонстрации «существенной позитивной динамики с точки зрения продвижения в мировых рейтингах в целом и особенно в рейтингах по отдельным предметным областям» [14, с. 222] оказалось недостаточно для формирования механизмов стратегического развития вузов, постановки работы по регулярной и последовательной нейтрализации имеющихся ресурсных разрывов.

Важность упорядочивания функционирования университетов [23, с. 232] в результате реализации проекта «5-100» не исключает того, что «ориентация... университета только на показатели конкретного рейтинга может быть сравнима с подготовкой школьника к... ЕГЭ..., когда... экзамен сдан, а с реальными знаниями по предмету... - проблемы» [23, с. 233].

Отдельные инициативы, например, «активная политика по привлечению зарубежных профессоров» [14, с. 223], не смогли обеспечить уровень ОР, необходимый для реализации стратегии развития, т.к. вузы не увязали ее с общим стратегическим процессом, с переходом по иерархии на высшие позиции инновационных способностей межфункционального взаимодействия [8]. «Стандартные решения - приглашение иностранных ученых - не работают» [13, c. 146]. Проблематика реализации проекта повышения международной конкурентоспособности находится в области происхождения целей и совершенствования взаимодействия стейкхолдеров в рамках стратегического процесса.

Теоретические концепции матрица власти Уинстанли, типология целей Пригожина в части субъектности целеполагания, а также утверждение Портера о приоритетности развития внутренних возможностей вступают в противоречие с формированием целевых установок проекта «5-100». 
Вместо того, чтобы начинать с совершенствования внутренних ресурсов и способностей, являющихся источником конкурентоспособности и отвечающих интересам ключевых заинтересованных сторон (клиентов и сотрудников), были заданы внешние (как по субъектности целеполагания - государственные, так и по направленности приложения усилий - международные) императивы развития. Правительство РФ, не ограничиваясь, как следовало бы, определением «правил игры» или «дистанцированной властью» [24, с. 46], фактически реализует права «полной власти», определяя условия госфинансирования и задавая извне вектор стратегического развития вуза.

Решение организационных проблем наряду с настройкой механизмов взаимодействия поможет российским университетам «попасть в создающееся международное пространство, провести реформирование и модернизацию образовательных систем, повысить конкурентоспособность выпускников» [9, с. 86].

\section{Материалы и результаты исследования}

Переходя к оценке практических аспектов функционирования университетов, отметим, что организационные изменения, связанные с ОР, осуществляются на основе организационной диагностики с целью поиска и нейтрализации организационных патологий. Общими и типичными характеристиками российских университетов, как объектов оценки, являются следующие:

1) образовательные услуги российских вузов являются массовыми, т. е. они не подбираются, не подстраиваются под клиентов, редко обновляются,

2) рынок услуг высшего образования является рынком продавца, т. к. большинство потребителей либо не самостоятельны (выбор вуза, программы обучения является результатом решения третьих лиц или происходит под давлением обстоятельств), либо делают выбор неосознанно, не понимая последствий,

3) университеты создают свой образовательный продукт без учета интересов внешних стейкхолдеров-потребителей (студентов) и будущих работодателей выпускников вузов, упрощая процесс ока- 
зания образовательных услуг. Не происходит фокусирования ни на продукте, являющимся лучшим выбором для продавцов стандартизованных продуктов, ни на процессе, который рекомендуется использовать продавцам кастомизированных ${ }^{1}$ услуг [22],

4) результаты проводимых в некоторых вузах - участниках программы «5-100» регулярных опросов потребителей и сотрудников не используются для обсуждения проблем с сотрудниками и для совместного поиска возможных вариантов управленческих решений, для совершенствования процесса оказания образовательных услуг, а «отдаются на откуп» руководящему составу вуза (первичного и среднего руководящего звена), который чаще всего либо не обращает на них внимания, либо принимает решения без вовлечения НПР,

5) отсутствие или несовершенство механизмов подотчетности руководства вуза как внешним (госнадзор, работодатели, потребители), так и внутренним (сотрудники вуза, включая НПР) стейкхолдерам,

6) выборы заведующего кафедрой, декана факультета или ректора вуза либо не проводятся, либо являются имитационными, не предполагающими ротации персонала - и только начиная с 01.08.2020 г. (01.07.2020 г. плюс 30 дней на приведение в соответствие с Трудовым кодексом уставов научных и образовательных организаций) «один и тот же человек не может занимать эту должность (ректора вуза) более трех сроков», а «трудовые договоры руководителей государственных и муниципальных научных организаций, а также глав государственных и муниципальных вузов будут заключаться на срок до пяти лет» [36],

7) противоречие между признаваемой ценностью НПР, как ключевых сотрудников, и срочностью их трудовых контрактов (обычной и повсеместной является порочная практика заключения договоров с НПР на 1-2 года), что не позволяет формировать устойчивые внутриорганизационные взаимодействия, препятствует созданию научных коллективов на кафедрах и факультетах,

${ }^{1}$ Кастомизация - приспособление продукта (товара или услуги) «к требованиям рынка»/к желаниям и потребностям покупателей; акцент - на гибкости процесса $[22$, c. 26$]$. 
8) «автаркия» подразделений вузов РФ, как организационная патология, препятствует формированию инновационной среды университета, условий для реализации на уровне одного субъекта преподавателя исследовательской, поисковой, ориентированной на получение нового знания, и образовательной деятельности (не являющейся инновационной),

9) помимо высокой квалификации преподавателя условием для создания условий осуществления инновационной исследовательской деятельности на институциональном уровне является «оптимальная организационная структура, обеспечивающая упорядоченность взаимодействия» [27, с. 189-190],

10) анализ дорожных карт университетов - участников проекта «5-100» показывает, что уровень компетенций преподавателей вузов недостаточен для достижения амбициозных задач [9, с. 86].

В ходе реализации проекта «5-100» проявляются противоречия целеполагания: между внешним (государственным, международным) признанием и внутренним (организационным) развитием. Складывается ситуация, когда вузам-участникам нечего предложить другим вузам в плане тиражирования лучших практик по развитию организационных способностей. Более того, происходит искажение стратегического пространства в отношении обеспечения равных ресурсных возможностей в процессе конкуренции между вузами РФ: одни университеты-участники проекта получают дополнительные преференции, а другие вузы лишены подобных финансовых преимуществ.

Поддержка одних участников рынка услуг высшего образования (потрачено более 70 млрд. руб. [35]) подрывает ресурсные возможности других вузов, лишенных целевого госфинансирования. Это препятствует формированию единого национального стратегического пространства, обеспечивающего равные условия конкуренции внутри отрасли высшего образования РФ.

Несмотря на значительную поддержку университетов из группы участников проекта им до сих пор так и не удалось справиться с автаркией подразделений, как с организационной патологией. 
Горизонтальные взаимодействия между подразделениями вуза являются скорее исключением, чем практикой. Финансовые потоки направляются на обеспечение результативности деятельности международных лабораторий вуза, работающих автономно от учебных структур университета: ни кафедры, ни НПР в научной работе лабораторий не участвуют.

Вместо этого вуз ограничивается материальным стимулированием индивидуальной исследовательской работы НПР, не поощряя создание научных коллективов на кафедрах и не оценивая соответствующим образом способности руководящего состава вуза на всех уровнях управления [10, с. 114]: «ограничивая область научных достижений исключительно финансовыми стимулами, администрация принижает чувство гордости ученого за результаты его работы».

Несмотря на то, что некоторые страны Западной Европы, ЮгоВосточной Азии и Западной Африки практикуют «продвижение... национальных элитных университетов» [25, с. 36], российскому государству необходимо предпринимать усилия не только для создания «Центров превосходства» на мировых рынках образования, но и обеспечивать равные условия для конкуренции внутри страны.

«Другие» вузы, не имея ни финансовых ресурсов на создание международных лабораторий и на приглашение ведущих профессоров из-за рубежа, ни организационных способностей внутри-вузовского взаимодействия решают проблему повышения публикационной активности по-своему, за счет исследовательского аутсорсинга, когда открытая вакансия «научного работника» предполагает полную автономность и самостоятельность в написании научных статей [34], что не способствует интеграции учебной и научной работы внутри вуза. Если «другим» университетам и удается обеспечивать повышение своей конкурентоспособности за счет развития внутренних возможностей, то это происходит скорее вопреки, чем благодаря проекту и никак не связано с тиражированием лучших практик ведущих университетов - участников проекта.

Еще одной особенностью проекта «5-100» является акцент на возрасте НПР. Вместо использования ресурсного подхода, акценти- 
рующего внимание на профессионализме сотрудников и развитии организационных способностях вуза, как источниках его конкурентоспособности, разработчики проекта необоснованно озаботились привлечением и закреплением одной возрастной группы НПР - молодежи. Но это не только не способствует созданию благоприятной атмосферы сотрудничества и доверия внутри коллектива вуза, но и противоречит действующему трудовому законодательству о недопущении дискриминации сотрудников по возрастному и иным признакам, не относящимся к профессиональной квалификации. Более того, подобное отношение к возрасту НПР не может являться образцом для формирования трудовых отношений в университетах, не участвующих в проекте «5-100». Реальными же причинами патологий «несовместимости личности с функцией» и «разрушения порядка» вузов являются:

1) отсутствие профессиональных требований к руководящему составу университетов, предусматривающих наличие высшей управленческой квалификации, подтвержденной дипломом МВА признанных (независимыми ассоциациями и рейтинговыми агентствами) на мировом уровне бизнес-школ [16, с. 131],

2) отсутствие, несовершенство или игнорирование принятых внутриорганизационных правил как по вертикальной, так и по горизонтальной ротации персонала, включая непрозрачные механизмы назначения и избрания на руководящие позиции всех уровней вуза.

\section{Обсуждение результатов исследования}

В условиях инновационной экономики роль сотрудников, вовлеченных в процесс постановки целей и разработки механизмов их реализации, и потребителей, оказывающих давление, «стимулирующее более быстрое продвижение инноваций» [18, с. 253], постоянно повышается.

Усиление конкуренции на рынке высшего образования РФ должно способствовать повышению значения не только потребителей, но и НПР. Реализация прав сотрудников как одной из важных заинтересованных сторон, готовых взять на себя ответственность за оперативные 
решения, должна происходить по согласованным заранее правилам. НПР является ключевой категорией персонала вуза, наиболее важной для достижения целей университета. Поэтому обеспечение формализации, закрепления перераспределения «операционной власти» в пользу НПР позволило бы создать и настроить работоспособные механизмы вовлечения НПР в приятие решений на всех уровнях и по всем направлениям [10, с. 103-105]: участие в управлении позволяет сформировать инновационную организационную среду, наладить горизонтальные межфункциональные взаимодействия; в лучших университетах мира модель «участия в управлении университетом» считается фундаментальным принципом всей университетской системы, создает условия для развития образования и исследований.

Развитие партнерских взаимоотношений и коллективной ответственности за будущее организации становится новым трендом в условиях инновационной экономики [15]. Разрешение проблем управления компании-лидеры инновационной экономики напрямую связывают с поиском компромисса между централизацией и делегированием полномочий, обеспечивая управляемость «сверху» и творческую инициативность «снизу» (на «месте действия») [17]. Системность держится на двух «столбах»: организационный порядок (управляемость) и динамика (активный персонал с высоким инновационным потенциалом) [20, с. 132].

В итоге, шаблонность заданного извне пассивного целеполагания, не предусматривающая последовательной реализации стратегического процесса, не смогла обеспечить полной реализации целей проекта «5-100».

\section{Заключение (выводы)}

Таким образом, проект «5-100» не смог сформировать механизмы устойчивого стратегического развития системы высшего образования России, как единой отрасли, способной как к сотрудничеству и интеграции, так и к противодействию негативным воздействиям со стороны участников международных рынков услуг высшего образования. 
В условиях инновационной экономики возрастает актуальность переформатирования систем целеполагания и управления университетами РФ:

1) необходима переориентация с институционального (правительство, вуз) на индивидуальный уровень (потребители, ключевые сотрудники),

2) высшее руководство обязано взять на себя стратегическую инициативу, но оно не может и не должно разрабатывать стратегию без вовлечения сотрудников в стратегический процесс [29, с. 563],

3) требуется ограничить срок замещения руководящих должностей на всех уровнях управления вуза - «даже гениальные администраторы управляют исходя из собственного видения; совмещение разных подходов и взглядов является важным условием построения сильного факультета, поэтому ротация руководителей позволит предотвратить его одностороннее развитие» [10, с. 112],

4) актуальность использования бюрократических ценностей в организациях снижается, когда успех зависит от способностей каждого сотрудника [15],

5) в условиях цифровой глобализации и инновационной экономики возрастает актуальность внедрения принципов организационной демократии [31],

6) необходимо обеспечить повышение управленческой квалификации менеджмента российских университетов в ведущих бизнесшколах мира «на базе программ, сопоставимых по содержанию и качеству с лучшими западноевропейскими... программами в области... менеджмента» [3],

7) следует «создавать постоянно действующую мотивирующую среду для плодотворной работы ученого... - наличие социальноправовой базы, гарантирующей сотруднику стабильную занятость на протяжении достаточно продолжительного отрезка времени, конкурентную заработную плату, удерживающую его от поиска работы в других организациях, достаточно свободный график рабочего времени, позволяющий заниматься научными изысканиями» $[9$, c. 87-89], 
8) необходимо внедрить механизмы трансформации руководителя университета в «креативного лидера», который «не только искренне радуется и поощряет высокие креативные достижения своих коллег, но и реально выстраивает стратегию создания условий и доверительной атмосферы» [11, с. 211].

Фрагментарность государственного регулирования реализации проекта «5-100» трансформируется в проблемы интернационализации вузов как сервисных организаций, осуществляющих экспорт образовательных услуг «поверх границ». Недостижение целей или невыполнение поставленных задач в полном объеме по проекту «5100», а также спровоцированное данным проектом искажение стратегического пространства отрасли образовательных услуг должны привести к пересмотру механизмов целеполагания вузов РФ, как с точки зрения субъектности, так и в отношении изменения акцентов развития.

Высокие места в международных рейтингах должны стать результатом, а не инструментом развития. Совершенствование внутренних возможностей или организационных способностей вузов позволит добиться более высоких результатов, свидетельствующих как о международной конкурентоспособности отдельных российских университетов, так и о высоком потенциале отрасли высшего образования РФ в целом.

\section{Список литературы}

1. О мерах по реализации государственной политики в области образования и науки [Электронный ресурс]: указ президента РФ от 7 мая 2012 года №599. Доступ из справ.-правовой системы «КонсультантПлюс».

2. Конкурсная документация по проведению открытого конкурса на предоставление господдержки университетам РФ [Электронный peсурс]: министерство образования и науки РФ, 2013. Доступ из справ.-правовой системы «КонсультантПлюс».

3. Концепция долгосрочного социально-экономического развития Российской Федерации на период до 2020 года [Электронный ресурс]: 
распоряжение правительства РФ от 17.11.2008 № 1662-р. Доступ из справ.-правовой системы «КонсультантПлюс».

4. Методические рекомендации по подготовке отчетов вузов [Электронный ресурс]: министерство образования и науки РФ, федеральное государственное автономное научное учреждение «Центр социологических исследований», 2016. Доступ из справ.-правовой системы «КонсультантПлюс».

5. О мерах государственной поддержки ведущих университетов Российской Федерации в целях повышения их конкурентоспособности среди ведущих мировых научно-образовательных центров [Электронный ресурс]: постановление правительства РФ от 16.03.2013 №211. Доступ из справ.-правовой системы «КонсультантПлюс».

6. Об утверждении плана мероприятий по развитию ведущих университетов, предусматривающих повышение их конкурентоспособности среди ведущих мировых научно-образовательных центров [Электронный ресурс]: распоряжение правительства РФ от 29.10.2012 № 2006-р (редакция от 12 марта 2016 г.). Доступ из справ.-правовой системы «КонсультантПлюс».

7. Перечень требований к отчетам по господдержке ведущим университетам РФ [Электронный ресурс]: министерство образования и науки РФ, 24.02.2014 №АП-166/02. Доступ из справ.-правовой системы «КонсультантПлюс».

8. Бахру А. Конкуренция на основе способностей. Кн. 3: Учеб. пособие: пер. с англ. Жуковский: МИМ ЛИНК, 2013. 88 с.

9. Бенсон Г. Ф. Компетенции современного преподавателя высшей школы в контексте интернационализации образования // Вестник ТГПУ (TSPU Bulletin). Томск: Изд-во ТГПУ, 2017. № 12 (189). C. 85-91.

10. Бычкова О. Участие в управлении университетом. СПб.: Центр исследований госуправления Европейский Университет в СПб, 2016. $124 \mathrm{c}$.

11. Галажинский Э.В., Кабрин В.И. Перспектива развития творческой личности трансфессионала в условиях смены научно-образователь- 
ной парадигмы университета // Вестник ТГУ. Томск: Изд-во ТГУ, 2019. № 447. С. 207-214.

12. Добреньков В.И., Кравченко А.И. Фундаментальная социология: в 15 т. Т. 13: Организация и управление. М.: ИНФРА-М, 2007. 942с.

13. Коржавина Н.П., Леонгардт В.А., Чикова О.А. Конкурентоспособность вузов на рынке образовательных услуг и рынке труда: взаимосвязь компонентов и показателей // Педагогическое образование в России. Екатеринбург: Изд-во УГПУ, 2016. № 8. С. 144-147.

14. Кузьминов Я. И. Университеты на перепутье: Высшее образование в России. М.: Изд. дом Высшей школы экономики, 2019. 318 с.

15. Мадьяров А.А. Народное предприятие как форма «организационной демократии» // IX Международный научный конгресс «Роль бизнеса в трансформации общества - 2014». М.: МФПУ «Синергия», 2014. С. 96-97.

16. Мадьяров А.А., Шамарова Г.М. Отечественный опыт конкурентоспособности вуза на рынке образовательных услуг // Современная конкуренция. М.: МФПУ «Синергия», 2015. Том 9. № 1 (49). C. 119-143.

17. Мадьяров А.А. Управление стратегическим развитием компании // IX Международный научный конгресс «Роль бизнеса в трансформации общества - 2014». М.: МФПУ «Синергия», 2014 г. С. 88-89.

18. Портер М. Конкуренция. М.: Изд. Дом. «Вильямс», 2005. 608 с.

19. Пригожин А.И. Дезорганизация: Причины, виды, преодоление. М.: Альпина Бизнес Букс, 2007. 402 с.

20.Пригожин А.И. Цели бизнеса: формирование и развитие // Общественные науки и современность. М.: Изд-во «РАН», 2015. № 1. C. 127-138.

21.Пригожин А.И. Цели и ценности. Новые методы работы с будущим. М.: Изд-во «Дело» АНХ, 2010. 432 с.

22. Робинсон С. Управление операциями. Кн. 5: Учеб. Пособие. Жуковский: МИМ ЛИНК, 2013. 104 с.

23. Халин В.Г. Глобальная конкурентоспособность ведущих университетов: модели и методы ее оценки и прогнозирования. М.: Проспект, 2018. 544 c. 
24. Ховард В. Организация: заинтересованные стороны, предназначение и ответственность. Кн. 4: Учеб. пособие. Жуковский: МИМ ЛИНК, 2013. $88 \mathrm{c}$.

25. Хубиев К.А., Макаров А.Н. К вопросу реформы аграрного образования: о парадоксах радикального единообразия, «точке невозврата» и концептуальных основах // Вопросы политической экономии, 2019. №3 (19). С. 34-55.

26. Щербина В.В., Попова Е.П. Вуз вне системы профессиональной подготовки специалистов как итог многолетних реформ российского высшего образования // Вестник РУДН. Серия: Социология, 2020. T. 20. № 3. C. 622-635.

27. Щербина В.В., Попова Е.П. Вуз как специфический тип организации, его функции и взаимоотношения с внешним окружением // Научный результат. Социология и управление, 2019. Т. 5. № 4. С. 184-199.

28. Щербина В.В., Попова Е.П. Организационное развитие: монография. М.: Школа издательского и медиа бизнеса, 2011. 297 с.

29. Gallos J.V. Organization development: a Jossey-Bass Reader. SanFrancisco: A Wiley Imprint, 2006, 1057 p.

30. Rigby D., Bilodeau B. Management Tools \& Trends, 2018. URL: https:// www.bain.com/contentassets/f8361c5cd99e4f40bbbf83c17d6a91b9/bain brief-management_tools_and_trends.pdf (дата обращения 25.11.2020).

31. The WorldBlu 10 Principles of Organizational Democracy. URL: https:// corporate-rebels.com/Blog/wp-content/uploads/2016/07/WorldBlu-10Principles-of-ODM.pdf (дата обращения 25.11.2020).

32. Wendell L.F., Cecil H.B. Organization development: behavior science interventions for organizational improvement. Harlow: Longman Higher Education, 1987, $352 \mathrm{p}$.

33. Wendell L. F., Cecil H. B. Organization development and transformation: managing effective change. NY: McGraw-Hill, 2005, 506 p.

34. Вакансия «Научный работник». URL: https://hh.ru/vacancy/39897854 (дата обращения 07.11.2020).

35. Ведущие российские вузы получили 70 миллиардов рублей за семь лет, 24.10.2019. URL: https://ria.ru/20191024/1560178810.html (дата обращения 24.11.2020). 
36. Путин подписал закон об увеличении предельного возраста ректоров вузов до 70 лет, 25.05.2020. URL: https://tass.ru/politika/8556579 (дата обращения 19.12.2020).

\section{References}

1. On measures to implement state policy in the field of education and science [Electronic resource]: decree of the President of the Russian Federation of May 7, 2012 No. 599. Access from the sprav.-legal system "ConsultantPlus".

2. Tender documentation for an open tender for the provision of state support to universities of the Russian Federation [Electronic resource]: Ministry of Education and Science of the Russian Federation, 2013. Access from the reference legal system "ConsultantPlus".

3. The concept of long-term socio-economic development of the Russian Federation for the period up to 2020 [Electronic resource]: order of the government of the Russian Federation of 17.11.2008 No. 1662-r. Access from the sprav.-legal system "ConsultantPlus".

4. Methodological recommendations for the preparation of reports of universities [Electronic resource]: Ministry of Education and Science of the Russian Federation, Federal State Autonomous Scientific Institution "Center for Sociological Research", 2016. Access from the reference legal system "ConsultantPlus".

5. On measures of state support of the leading universities of the Russian Federation in order to increase their competitiveness among the world's leading research and educational centers [Electronic resource]: RF government decree of March 16, 2013 No. 211. Access from the sprav.-legal system "ConsultantPlus".

6. On the approval of the action plan for the development of leading universities, providing for increasing their competitiveness among the world's leading scientific and educational centers [Electronic resource]: order of the Government of the Russian Federation of October 29, 2012 No. 2006-r (as amended on March 12, 2016 .). Access from the sprav.-legal system "ConsultantPlus".

7. List of requirements for reports on state support to the leading universities of the Russian Federation [Electronic resource]: Ministry of Educa- 
tion and Science of the Russian Federation, 24.02.2014 No. AP-166/02. Access from the sprav.-legal system "Consultant-Plus".

8. Bahru A. Konkurentsiya na osnove sposobnostey [Ability-Based Competition]. Book 3. MIM LINK, 2013. 88p.

9. Benson G. F. Vestnik TGPU (TSPU Bulletin). Tomsk: TSPU Publishing house, 2017. No. 12 (189). P. 85-91.

10. Bychkova O. Uchastie v upravlenii universitetom [Participation in university management]. Saint Petersburg: Center for Public Administration Research European University in Saint Petersburg, 2016.124 p.

11. Galazhinskiy E. V., Kabrin V. I. Vestnik TGU. Tomsk: TSU Publishing House, 2019. No. 447. P. 207-214.

12. Dobren'kov V. I., Kravchenko A. I. Fundamental'naya sotsiologiya: v 15 t. T. 13: Organizatsiya $i$ upravlenie [Fundamental sociology: in 15 volumes. V. 13: Organization and management]. M.: INFRA-M, 2007. $942 \mathrm{p}$.

13. Korzhavina N. P., Leonhardt V. A., Chikova O. A. Pedagogicheskoe obrazovanie v Rossii [Pedagogical education in Russia]. Yekaterinburg: UGPU Publishing House, 2016. No. 8. P. 144-147.

14. Kuz'minov Ya. I. Universitety na pereput'e: Vysshee obrazovanie v Rossii [Universities at a crossroads: Higher education in Russia]. Moscow: Higher School of Economics, 2019. 318 p.

15. Madyarov A. A. IX Mezhdunarodnyy nauchnyy kongress «Rol' biznesa $v$ transformatsii obshchestva - 2014» [IX International Scientific Congress "The Role of Business in the Transformation of Society - 2014"]. M.: MFPU "Synergy", 2014. P. 96-97.

16. Mad'yarov A. A., Shamarova G. M. Sovremennaya konkurentsiya [Modern competition]. Moscow: MFPU “Synergy”, 2015. Vol. 9, No. 1 (49). P. 119-143.

17. Madyarov A.A. IX Mezhdunarodnyy nauchnyy kongress «Rol' biznesa $v$ transformatsii obshchestva - 2014» [IX International Scientific Congress "The Role of Business in the Transformation of Society - 2014"]. M.: MFPU "Synergy", 2014. P. 88-89.

18. Porter M. Konkurentsiya [Competition]. Moscow: Williams Ed. House., 2005. $608 \mathrm{p}$. 
19. Prigozhin A. I. Dezorganizatsiya: Prichiny, vidy, preodolenie [Disorganization: Reasons, types, overcoming]. M.: Alpina Business Books, 2007. 402 p.

20.Prigozhin A. I. Obshchestvennye nauki i sovremennost' [Social sciences and modernity]. M.: RAS Publishing house, 2015. No. 1. P. 127-138.

21.Prigozhin A. I. Tseli $i$ tsennosti. Novye metody raboty s budushchim [Goals and values. New methods of working with the future]. M.: "Delo" ANKh Publishing house, 2010. 432 p.

22. Robinson S. Upravlenie operatsiyami [Operations management]. Book 5. Zhukovsky: MIM LINK, 2013. 104p.

23. Khalin V. G. Global'naya konkurentosposobnost'vedushchikh universitetov: modeli i metody ee otsenki i prognozirovaniya [Global competitiveness of leading universities: models and methods for its assessment and forecasting]. Moscow: Prospect, 2018. 544 p.

24. Howard V. Organizatsiya: zainteresovannye storony, prednaznachenie $i$ otvetstvennost'[Organization: stakeholders, mission and responsibility]. Book 4. Zhukovsky: MIM LINK, 2013. 88p.

25. Khubiev K. A., Makarov A. N. Voprosy politicheskoy ekonomi [Problems of Political Economy], 2019. No. 3 (19). P. 34-55.

26. Shcherbina V. V., Popova E. P. Vestnik RUDN. Seriya: Sotsiologiya [Bulletin of RUDN. Series: Sociology], 2020. V. 20. No. 3. P. 622-635.

27. Shcherbina V. V., Popova E. P. Nauchnyy rezul 'tat. Sotsiologiya i upravlenie [Scientific result. Sociology and Management], 2019. V. 5. No. 4. P.184-199.

28. Shcherbina V. V., Popova E. P. Organizatsionnoe razvitie [Organizational development]: monograph. Moscow: School of Publishing and Media Business, 2011. 297 p.

29. Gallos J. V. Organization development: a Jossey-Bass Reader. San-Francisco: A Wiley Imprint, 2006, 1057 p.

30.Rigby D., Bilodeau B. Management Tools \& Trends, 2018. URL: https://www.bain.com/contentassets/f8361c5cd99e4f40bbbf83c17d6a91b9/bain_brief -management_tools_and_trends.pdf (accessed 25.11.2020). 
31. The WorldBlu 10 Principles of Organizational Democracy. URL: https://corporate-rebels.com/Blog/wp-content/uploads/2016/07/WorldBlu-10-Principles-of-ODM.pdf (accessed 11/25/2020).

32. Wendell L. F., Cecil H. B. Organization development: behavior science interventions for organizational improvement. Harlow: Longman Higher Education, 1987, $352 \mathrm{p}$.

33. Wendell L. F., Cecil H. B. Organization development and transformation: managing effective change. NY: McGraw-Hill, 2005, 506 p.

34. Vacancy "Scientist". URL: https://hh.ru/vacancy/39897854 (accessed $11 / 07 / 2020)$.

35. Leading Russian universities received 70 billion rubles in seven years, October 24, 2019. URL: https://ria.ru/20191024/1560178810.html (accessed 11/24/2020).

36. Putin signed a law to increase the age limit for university rectors to 70 years, 05/25/2020. URL: https://tass.ru/politika/8556579 (accessed $12 / 19 / 2020)$.

\section{ДАННЫЕ ОБ АВТОРЕ}

Мадьяров Азат Альбертович, независимый исследователь / эксперт по стратегическому менеджменту, кандидат социологических наук, МBA

Институт гуманитарных наук, экономики и информационных наук

ул. Ангела Димитрова, 88, г. Бургас, Болгария am.72@mail.ru

\section{DATA ABOUT THE AUTHOR}

Madyarov Azat Albertovich, independent researcher/ independent expert on strategical management, $\mathrm{PhD}$ of sociological sciences, MBA Institute of Humanities, Economics and Information Technology 88, Angela Dimitrova Str., Burgas, Bulgaria am.72@mail.ru

SPIN-code: 1578-2214

ORCID: 0000-0002-4911-7790

Researcher ID: C-5293-2017 